\title{
Different scenarios for inverse estimation of soil hydraulic parameters from double-ring infiltrometer data using HYDRUS-2D/3D
}

\author{
Parisa Mashayekhi', Shoja Ghorbani-Dashtaki'*, Mohammad Reza Mosaddeghi², Hossein Shirani ${ }^{3}$, \\ and Ali Reza Mohammadi Nodoushan ${ }^{4}$
}

\author{
${ }^{1}$ Department of Soil Science, College of Agriculture, Shahrekord University, Shahrekord 88186-34141, Iran \\ ${ }^{2}$ Department of Soil Science, College of Agriculture, Isfahan University of Technology, Isfahan 84156-83111, Iran \\ ${ }^{3}$ Department of Soil Science, College of Agriculture, Vali-e-Asr University, Rafsanjan, Iran \\ ${ }^{4}$ Department of Computer Engineering, Faculty of Engineering, Vali-e-Asr University, Rafsanjan, Iran
}

Received October 25, 2015; accepted April 1, 2016

A b s t r a c t. In this study, HYDRUS-2D/3D was used to simulate ponded infiltration through double-ring infiltrometers into a hypothetical loamy soil profile. Twelve scenarios of inverse modelling (divided into three groups) were considered for estimation of Mualem-van Genuchten hydraulic parameters. In the first group, simulation was carried out solely using cumulative infiltration data. In the second group, cumulative infiltration data plus water content at $h=-330 \mathrm{~cm}$ (field capacity) were used as inputs. In the third group, cumulative infiltration data plus water contents at $h=-330 \mathrm{~cm}$ (field capacity) and $h=-15000 \mathrm{~cm}$ (permanent wilting point) were used simultaneously as predictors. The results showed that numerical inverse modelling of the double-ring infiltrometer data provided a reliable alternative method for determining soil hydraulic parameters. The results also indicated that by reducing the number of hydraulic parameters involved in the optimization process, the simulation error is reduced. The best one in infiltration simulation which parameters $\alpha, n$, and $K_{\mathrm{s}}$ were optimized using the infiltration data and field capacity as inputs. Including field capacity as additional data was important for better optimization/definition of soil hydraulic functions, but using field capacity and permanent wilting point simultaneously as additional data increased the simulation error.

K e y w or d s: double-ring infiltrometer, Mualem-van Genuchten model, HYDRUS-2D/3D, inverse modelling, statistical criteria

\section{INTRODUCTION}

The vadose zone has a fundamental role in many aspects of hydrology, including infiltration, soil moisture storage, evaporation, plant water uptake, groundwater recharge, runoff, and erosion (Nakhaei and Šimůnek, 2014). Knowledge of the hydraulic properties of unsaturated soils (ie the reten-

*Corresponding author e-mail: ghorbani-sh@agr.sku.ac.ir tion curve, $\theta(h)$, and the hydraulic conductivity functions, $K(h)$ ) is essential for most or all studies involving water flow and solute transport in the vadose zone (Bitterlich et al., 2004). Most traditional methods to determine these properties require relatively restrictive initial and boundary conditions, and thus can be time-consuming, laborious, and expensive. Moreover, data from accurate but small-scale laboratory measurements could hardly ever be transferred to the field scale (Asgarzadeh et al., 2014).

Significant advances in computational capabilities in the 1980s have stimulated research on the use of inverse modelling for estimation of the soil retention and unsaturated hydraulic conductivity functions (Wöhling and Vrugt, 2011). In this method, the numerical solution of the Richards equation is utilized for estimation of the soil hydraulic parameters. The numerical solution of the Richards equation requires an iterative implicit technique with fine discretization in space, which results in a tedious solving process (Damodhara Rao et al., 2006). Based on the finite element method, the HYDRUS-1D and HYDRUS-2D/3D codes were developed to solve the Richards equation and have been widely used to simulate one-dimensional and two- and three-dimensional water movement in variably saturated media (Šimůnek et al., 2011).

HYDRUS software is one of the most complete packages for simulating water, heat, and solute movement in both two- and three-dimensional variably saturated and porous media (Šimůnek et al., 2008). Many investigators have used this software to evaluate either field or laboratory experiments or other mathematical models (Alletto et al.,

(C) 2016 Institute of Agrophysics, Polish Academy of Sciences 
2015; El-Nesr et al., 2014; Kandelous and Šimůnek, 2010; Pollalis and Valiantzas, 2015; Ramos et al., 2012; Rashid et $a l ., 2015)$. The HYDRUS model enables its users to trace the movement of water and solutes and the wetting patterns in both simple and complex geometries for homogeneous or heterogeneous soils and for different combinations of initial and boundary conditions (El-Nesr, 2014).

In recent years, analysis of water infiltration experimental data has become a widely used practice for obtaining soil hydraulic properties through the inverse modelling. The infiltration rate and its variation with time depend upon the initial water content, as well as on the texture, structure, and uniformity (or layering sequence) of the soil profile (Reynolds et al., 2002a, b). Considerable attention has been given to the prediction of soil hydraulic properties from ponded or tension infiltration experiments (Bohne et al., 1993; Russo et al., 1991; Šimůnek and van Genuchten, 1996). The double-ring infiltrometer is a standard, well-known, and widely used instrument for in situ measurements of infiltration. However, there are relatively few studies on the accuracy of measured infiltration data via this method for reliable estimation of soil hydraulic parameters.

Russo et al. (1991) and Šimůnek and van Genuchten (1996) reported that the cumulative infiltration data of ponded and tension infiltration experiments does not provide enough information to obtain a unique set of optimized parameters. It is commonly reported that some additional information is needed to obtain unique solutions for a large number of parameters. Such additional information could include water contents and/or pressure heads (Šimůnek and van Genuchten, 1996), solute concentrations (Abbasi et al., 2003), or temperatures (Nakhaei and Šimůnek, 2014) measured at a certain depth in the soil profile. However, little is known about the effect of including additional data as a predictor on the efficiency and uniqueness of inverse modelling of double-ring infiltrometer data.

The objectives of this study were:

- to identify the suitability of cumulative infiltration data derived from a double-ring infiltrometer for the estimation of soil hydraulic parameters,

- to determine the best combination of hydraulic parameters to be optimized with acceptable precision, and

- to investigate whether additional information (FC, PWP or FC + PWP) can improve water flow simulation and reduce the uncertainty of the optimized hydraulic parameters.

\section{MATERIAL AND METHODS}

At first, double-ring infiltration data were numerically generated for a hypothetical loamy soil through direct simulation by HYDRUS-2D/3D (Šimůnek et al., 2011). The Mualem-van Genuchten hydraulic parameters of the hypothetical loam soil were determined via class pedo-transfer functions (PTFs) of Rosetta Lite (Schaap et al., 2001), which is embedded in the HYDRUS software package, as follows: residual water content $\left(\theta_{\mathrm{r}}\right)=0.078 \mathrm{~cm}^{3} \mathrm{~cm}^{-3}$, saturated water content $\left(\theta_{\mathrm{s}}\right)=0.430 \mathrm{~cm}^{3} \mathrm{~cm}^{-3}$, scaling parameter $(\alpha)=0.036 \mathrm{~cm}^{-1}$, shape parameter $(n)=1.56$, saturated hydraulic conductivity $\left(K_{\mathrm{s}}\right)=0.00028 \mathrm{~cm} \mathrm{~min}^{-1}$, and poreconnectivity parameter $(l)=0.5$.

For simulation of ponded infiltration processes through the double-ring infiltrometer, an axisymmetric domain of $150 \mathrm{~cm}$ in both depth and length was considered. The inner and outer ring radii were 15 and $30 \mathrm{~cm}$, respectively, and the insertion depth of the rings was considered to be $7 \mathrm{~cm}$. The initial condition of the simulation domain was given in the form of the soil water pressure head. The soil water content was assumed to be variable along the profile. In this way, the soil water pressure head was linearly distributed with depth, so the pressure head at the soil surface was considered to be $-10000 \mathrm{~cm}$ and increased linearly with depth up to the pressure head of $-4000 \mathrm{~cm}$ at the bottom of the domain. A constant water head $(h=10 \mathrm{~cm})$ was considered for the inlet boundary conditions of both inner ring and outer ring areas, respectively. The soil surface out of the area of the rings was subjected to the atmospheric boundary conditions. No flux boundary was considered for the vertical boundaries of the simulation domain and along the ring walls and the bottom boundary condition was considered as free drainage. The final time for simulation was set to $300 \mathrm{~min}$. The well-known Mualem-van Genuchten soil hydraulic model (Mualem, 1976; van Genuchten, 1980), embedded in the HYDRUS software package, was selected for the numerical simulations.

Sensitivity analysis is an essential aspect of analytical and numerical models (Fuladipanah, 2012). Therefore, the infiltration data obtained through direct simulation by HYDRUS-2D/3D were used to calculate the sensitivities of the cumulative infiltration data to the Mualem-van Genuchten function parameters (including $K_{\mathrm{s}}, \theta_{\mathrm{s}}, \theta_{\mathrm{r}}, n, \alpha$, and $l$ ). The sensitivity coefficient, $S\left(t, b_{j}\right)$, was calculated as follows (Abbasi, 2015 and Šimůnek et al., 1998):

$$
S\left(t, b_{j}\right)=\frac{\left|Y\left(b_{j}+\Delta b_{j} e_{j}\right)-Y\left(b_{j}\right)\right|}{Y\left(b_{j}\right)},
$$

where: $S\left(t, b_{j}\right)$ is the change in the variable $Y$ (cumulative infiltration, $\mathrm{cm}^{3}$ ) corresponding to a $1 \%$ change in parameter $b, e_{\mathrm{j}}=j$ th unit vector, and $\Delta b=0.01 b$. Sensitivity coefficients would characterize the behaviour of the objective function in the parameter space (Šimůnek et al., 1998).

In the final stage, infiltration data obtained in the first stage were used as input data for the optimization of the Mualem-van Genuchten hydraulic parameters by inverse modelling. The HYDRUS-2D/3D code uses LevenbergMarquardt optimization algorithm for the inverse estimation (Šimůnek et al., 2011). In this study, twelve different scenarios were considered for inverse estimation of the soil 
hydraulic parameters (Table 1). In the first four scenarios, the optimization was done solely using the infiltration data. In scenario 1, five parameters of the Mualem-van Genuchten model including $K_{\mathrm{s}}, \theta_{\mathrm{s}}, \theta_{\mathrm{r}}, n$, and $\alpha$ were selected as unknown parameters to be optimized via the inverse solution using the cumulative infiltration data. In scenario 2, we considered four hydraulic parameters $\left(K_{\mathrm{s}}, \theta_{\mathrm{s}}, n\right.$, and $\left.\alpha\right)$ as unknown parameters. In scenario 3, three parameters were optimized $\left(K_{\mathrm{s}}, n\right.$, and $\left.\alpha\right)$. In scenario 4, two parameters were optimized $\left(K_{\mathrm{s}}\right.$ and $\left.n\right)$. Scenarios 5-8 were correspondingly similar to scenarios 1-4 but field capacity (FC) was also included as an additional predictor. Scenarios 9-12 were similar to scenarios 5-8, but permanent wilting point (PWP) was also added as an input.

In order to validate the numerical simulation by HYDRUS-2D/3D for the before-mentioned scenarios and to select the best scenario(s) for optimization of soil hydraulic parameters, generated and simulated cumulative infiltration data at 17 discretized times including $1,2,5,10$, $15,20,30,45,60,90,120,150,180,210,240,270$, and 300 min were used for statistical comparisons. Statistical criteria of the coefficient of determination $\left(\mathrm{R}^{2}\right)$, sum squares of errors $\left[S S E,\left(\mathrm{~cm}^{3}\right)^{2}\right]$, root mean squares of errors (RMSE, $\left.\mathrm{cm}^{3}\right)$, and mean bias error $\left(M B E, \mathrm{~cm}^{3}\right)$ were calculated as follows:

$$
\begin{gathered}
\mathrm{R}^{2}=\left(\frac{N\left(\sum_{i=1}^{N} I_{i} \hat{I}_{i}\right)-\left(\sum_{i=1}^{N} I_{i}\right)\left(\sum_{i=1}^{N} \hat{I}_{i}\right)}{\left.\sqrt{\left[N \sum_{i=1}^{N} I_{i}^{2}-\left(\sum_{i=1}^{N} I_{i}\right)^{2}\right]\left[N \sum_{i=1}^{N} \hat{I}_{i}^{2}-\left(\sum_{i=1}^{N} \hat{I}\right)_{i}^{2}\right]}\right)}\right. \\
S S E=\sum_{i=1}^{N}\left(I_{i}-\hat{I}_{i}\right)^{2} \\
R M S E=\sqrt{\frac{\sum_{i=1}^{N}\left(I_{i}-\hat{I}_{i}\right)^{2}}{N}} \\
M B E=\frac{\sum_{i=1}^{N}\left(I_{i}-\hat{I}_{i}\right)}{N}
\end{gathered}
$$

T a b l e 1. Generated and simulated cumulative infiltration data by HYDRUS-2D/3D at specified discretized times

\begin{tabular}{cccccccccccccc}
\hline \multirow{2}{*}{$\begin{array}{c}\text { Time } \\
(\mathrm{min})\end{array} \begin{array}{c}\text { Gene- } \\
\begin{array}{c}\text { rated } \\
\text { data } \\
\left(\mathrm{cm}^{3}\right)\end{array}\end{array}$} & $1^{*}$ & 2 & 3 & 4 & 5 & 6 & 7 & 8 & 9 & 10 & 11 & 12 \\
\hline 1 & 332.1 & 376.6 & 346.1 & 328.1 & 349.3 & 344.3 & 338.9 & 337.1 & 332.7 & 345.5 & 349.8 & 305.3 & 332.7 \\
2 & 480.5 & 522.0 & 493.6 & 476.5 & 492.6 & 491.9 & 487.2 & 485.8 & 479.7 & 492.4 & 498.7 & 453.9 & 480.8 \\
5 & 775.1 & 813.1 & 790.4 & 771.7 & 782.2 & 788.7 & 781.0 & 779.3 & 771.5 & 786.1 & 795.8 & 754.1 & 773.2 \\
10 & 1108.7 & 1143.6 & 1126.3 & 1106.1 & 1113.0 & 1124.9 & 1113.3 & 1111.6 & 1102.2 & 1116.8 & 1130.8 & 1093.7 & 1104.3 \\
15 & 1373.9 & 1406.0 & 1394.9 & 1372.2 & 1376.7 & 1393.7 & 1377.8 & 1376.1 & 1365.3 & 1380.1 & 1398.4 & 1364.0 & 1368.0 \\
20 & 1597.5 & 1625.3 & 1620.2 & 1596.4 & 1599.3 & 1619.2 & 1600.8 & 1598.9 & 1587.1 & 1602.8 & 1622.7 & 1591.2 & 1590.0 \\
30 & 1987.5 & 2001.8 & 2007.4 & 1986.9 & 1987.8 & 2007.2 & 1989.7 & 1987.6 & 1974.6 & 1991.6 & 2008.2 & 1986.8 & 1977.9 \\
45 & 2344.2 & 2343.4 & 2356.7 & 2344.3 & 2344.1 & 2357.1 & 2345.6 & 2343.7 & 2329.8 & 2346.4 & 2355.7 & 2348.1 & 2333.7 \\
60 & 2950.7 & 2925.6 & 2946.1 & 2951.3 & 2949.3 & 2947.2 & 2950.3 & 2948.8 & 2934.6 & 2947.8 & 2943.6 & 2960.3 & 2938.7 \\
90 & 3740.8 & 3698.4 & 3720.6 & 3742.2 & 3739.4 & 3722.0 & 3738.4 & 3738.1 & 3725.3 & 3731.6 & 3717.6 & 3755.0 & 3729.1 \\
120 & 4453.2 & 4410.0 & 4429.2 & 4454.3 & 4450.9 & 4430.2 & 4449.4 & 4449.3 & 4440.1 & 4440.9 & 4426.4 & 4468.2 & 4443.3 \\
150 & 5112.5 & 5079.6 & 5091.3 & 5112.2 & 5110.4 & 5092.3 & 5108.2 & 5108.6 & 5102.2 & 5100.5 & 5089.5 & 5125.7 & 5104.7 \\
180 & 5757.9 & 5739.8 & 5743.9 & 5756.6 & 5756.8 & 5744.6 & 5754.1 & 5755.1 & 5752.1 & 5749.6 & 5742.8 & 5767.2 & 5753.5 \\
210 & 6408.3 & 6400.3 & 6402.7 & 6406.3 & 6407.1 & 6402.7 & 6405.3 & 6406.6 & 6407.3 & 6404.3 & 6402.2 & 6412.2 & 6408.1 \\
240 & 7032.8 & 7041.7 & 7035.9 & 7028.9 & 7033.1 & 7035.5 & 7031.2 & 7032.3 & 7037.5 & 7034.6 & 7036.2 & 7030.8 & 7036.8 \\
270 & 7634.7 & 7655.4 & 7644.9 & 7628.6 & 7635.3 & 7644.3 & 7635.5 & 7635.0 & 7644.0 & 7642.4 & 7646.0 & 7625.2 & 7643.4 \\
300 & 8199.6 & 8234.7 & 8216.6 & 8191.6 & 8201.3 & 8215.9 & 8205.5 & 8201.6 & 8216.5 & 8213.6 & 8218.5 & 8183.6 & 8213.8 \\
\hline
\end{tabular}

*Number of scenario. 
In all the above formulas, $I_{i}$ and $\hat{I}_{i}$ are observed and predicted values of cumulative infiltration $\left(\mathrm{cm}^{3}\right)$ at the discretized time, respectively, $\bar{I}$ is the mean of the observed infiltration values $\left(\mathrm{cm}^{3}\right)$, and $N$ is the number of the discretized times. Positive $M B E$ indicates that the model predictions are greater than the measured values, and negative $M B E$ indicates that the measured values are greater than the values predicted by the model. However, the absolute value of $M B E$ was used for the comparison of the models.

Since different numbers of inputs were used in the different scenarios, the Akaike information criterion $(A I C)$ was also used to compare the efficiency of the derived model in different scenarios by considering a penalty for scenarios with a higher number of inputs (Akaike, 1974). The AIC was calculated using:

$$
A I C=2 K+N \ln \left(\frac{S S E}{N}\right)
$$

where: $K$ is the number of adjustable parameters in the model, $N$ is the number of data points (ie infiltration) to be fitted (in this study, $N=17$ ) and $S S E$ is the sum squares of errors. Because $N$ is small in this study, a version of Eq. (6) was used to calculate the corrected $A I C\left(A I C_{c}\right)$ :

$$
A I C_{c}=A I C+\frac{2 K(K+1)}{N-K+1} .
$$

According to Burnham and Anderson (2004), Eq. (7) should be used unless $N / K$ is greater than about 40 . In our case, this ratio is much lower than 40 . The absolute values of $A I C$ and $A I C_{C}$ depend on the units of the properties included in the model and the sample size, but the difference $(\Delta)$ between the values of $A I C$ or $A I C_{c}$ for two models is proposed for the efficiency comparison. Models having $\Delta \leq 2$ have substantial support (evidence), those with $4 \leq \Delta \leq 7$ have considerably less support, and models with $\Delta>10$ have essentially no support. The model with a lower value of $A I C$ or $A I C_{c}$ is the better one (Burnham and Anderson, 2004).

The index of agreement $(d)$, as a standardized measure of the degree of the model prediction error (Willmott, 1981), was also calculated:

$$
d=1-\frac{\sum_{i=1}^{N}\left(I_{i}-\hat{I}_{i}\right)^{2}}{\sum_{i=1}^{N}\left(\left|\hat{I}_{i}-I\right|+\left|I_{i}-I\right|\right)^{2}} .
$$

The $d$ varies between 0 and 1 ; a value of 1 indicates a perfect match, and 0 indicates no agreement at all (Willmott, 1981).

The efficiency coefficient $(E F)$ proposed by Nash and Sutcliffe (1970) was calculated as:

$$
E F=1-\frac{\sum_{i=1}^{N}\left(I_{i}-\hat{I}_{i}\right)^{2}}{\sum_{i=1}^{N}\left(I_{i}-\bar{I}\right)^{2}} .
$$

This coefficient ranges from $-\infty$ to $1 . E F=1$ indicates a perfect fit while values below 0 result from a worse fit than the average of observations.

\section{RESULTS}

The cumulative infiltration data ( $I$ vs. time) that were generated numerically by the HYDRUS-2D/3D for a double-ring infiltration experiment in a hypothetical loamy soil are shown in Fig. 1.

The sensitivity analysis of the cumulative infiltration to one percent change in soil hydraulic parameters is presented in Fig. 2. The results indicate that the cumulative infiltration, measured by the double-ring infiltrometer, is most sensitive to the parameter $K_{\mathrm{s}}$. In addition, the sensitivity of simulations to $K_{\mathrm{s}}$ is time-dependent and increases with time. Following $K_{\mathrm{s}}$, the highest sensitivity coefficient belonged to $n$ and $\theta_{\mathrm{s}}$, respectively. The sensitivities of ponded infiltration to $\theta_{\mathrm{r}}$ and $\alpha$ were relatively much smaller and the pore-connectivity parameter $(l)$ was the least sensitive parameter (Fig. 2).

Cumulative infiltration data generated and simulated by HYDRUS-2D/3D at 17 specified discretized times are presented in Table 1. The results of estimation of the soil hydraulic parameters by HYDRUS-2D/3D for different scenarios are summarized in Table 2. Table 3 presents the calculated statistical criteria for the simulation assessment of

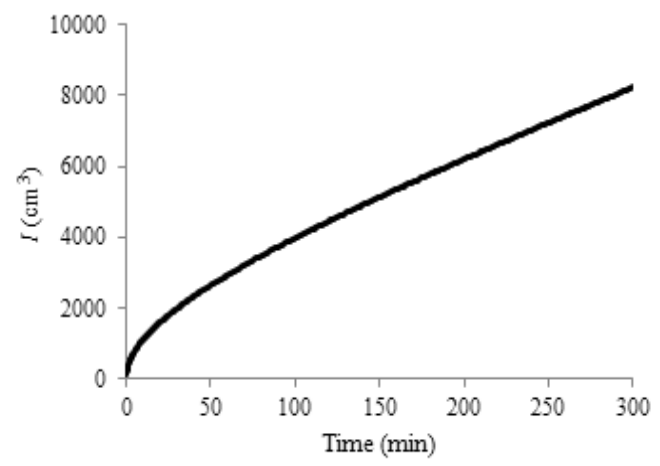

Fig. 1. Cumulative infiltration $(I)$ versus time for a hypothetical double-ring infiltration experiment.

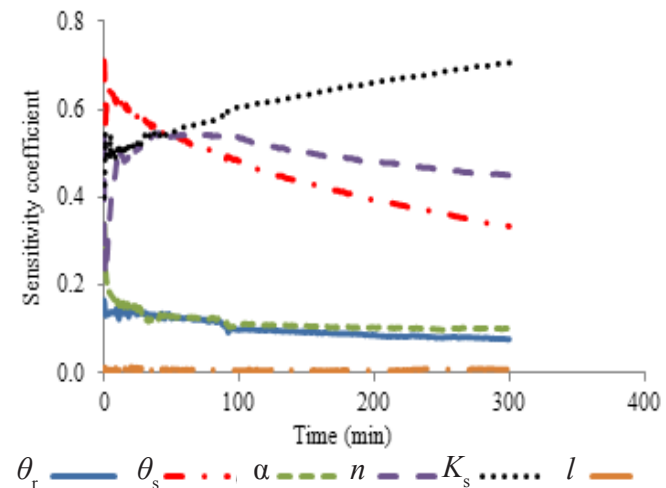

Fig. 2. Sensitivity analysis of the cumulative infiltration $(I)$ versus time to a $1 \%$ change in different soil hydraulic parameters. 
different optimization scenarios. According to Table 3, the scenarios were ranked based on each statistical criterion. Therefore, scenario(s) with the lowest values of defined statistical criteria (ie SSE, RMSE, MBE, and $A I C_{c}$ ) were assigned the best one(s) in the ranking.

Since the values of the coefficient of determination $\left(\mathrm{R}^{2}\right), d$ index, and efficiency coefficient $(E F)$ were the same in all scenarios, these criteria were not used for the effi- ciency ranking. The scenario(s) with the lowest overall score would be regarded the best one(s) and will impose the least error into the cumulative infiltration simulation. The results of ranking according to the five criteria, including SSE, RMSE, MBE, and AIC, are given in Table 4. Figure 3 shows an example of the output simulated by the HYDRUS-2D/3D for scenarios 1,5 , and 9. It shows the final spatial distribution of water contents in the soil profile at the end of the 300 min simulation.

T a b l e 2. Optimized soil hydraulic parameters by HYDRUS-2D/3D for different scenarios

\begin{tabular}{|c|c|c|c|c|c|c|c|c|c|c|}
\hline \multirow{3}{*}{ Scenario } & \multicolumn{5}{|c|}{ Fitted parameters } & \multicolumn{5}{|c|}{ Optimized values of hydraulic parameters } \\
\hline & $\theta_{\mathrm{r}}$ & $\theta_{\mathrm{s}}$ & $\alpha$ & \multirow{2}{*}{$n$} & $K_{s}$ & $\theta_{\mathrm{r}}$ & $\theta_{\mathrm{s}}$ & $\alpha$ & \multirow{2}{*}{$n$} & $K_{s}$ \\
\hline & $(\mathrm{cm}$ & & $\left(\mathrm{cm}^{-1}\right)$ & & $\left.(\mathrm{cm} \mathrm{min})^{-1}\right)$ & \multicolumn{2}{|c|}{$\left(\mathrm{cm}^{3} \mathrm{~cm}^{-3}\right)$} & $\left(\mathrm{cm}^{-1}\right)$ & & $\left.(\mathrm{cm} \mathrm{min})^{-1}\right)$ \\
\hline \multicolumn{11}{|c|}{$I$} \\
\hline 1 & + & + & + & + & + & $\begin{array}{c}0.126 \\
(-0.161-0.414)^{*}\end{array}$ & $\begin{array}{c}0.451 \\
(0.209-0.693)\end{array}$ & $\begin{array}{c}0.0007 \\
(0.0003-0.003)\end{array}$ & $\begin{array}{c}1.42 \\
(0.16-1.07)\end{array}$ & $\begin{array}{c}0.0027 \\
(-0.001-0.002)\end{array}$ \\
\hline 2 & - & + & + & + & + & - & $\begin{array}{c}0.281 \\
(0.251-0.311)\end{array}$ & $\begin{array}{c}0.01 \\
(-0.001-0.01)\end{array}$ & $\begin{array}{c}2.56 \\
(1.01-4.11)\end{array}$ & $\begin{array}{c}0.01 \\
(0.00004-0.01)\end{array}$ \\
\hline 3 & - & - & + & + & + & - & - & $\begin{array}{c}0.04 \\
(0.037-0.039)\end{array}$ & $\begin{array}{c}1.60 \\
(1.59-1.61)\end{array}$ & $\begin{array}{c}0.02 \\
(0.0170-0.0173)\end{array}$ \\
\hline 4 & - & - & - & + & + & - & - & - & $\begin{array}{c}1.55 \\
(1.53-1.56)\end{array}$ & $\begin{array}{c}0.017 \\
(0.017-0.018)\end{array}$ \\
\hline \multicolumn{11}{|c|}{$I+F C$} \\
\hline 5 & + & + & + & + & + & $\begin{array}{c}0.127 \\
(0.067-0.188)\end{array}$ & $\begin{array}{c}0.334 \\
(0.274-0.393)\end{array}$ & $\begin{array}{c}0.01 \\
(-0.001-0.004)\end{array}$ & $\begin{array}{c}2.60 \\
(0.13-5.33)\end{array}$ & $\begin{array}{c}0.01 \\
(0.003-0.02)\end{array}$ \\
\hline 6 & - & + & + & + & + & - & $\begin{array}{c}0.423 \\
(0.418-0.429)\end{array}$ & $\begin{array}{c}0.03 \\
(0.029-0.033)\end{array}$ & $\begin{array}{c}1.52 \\
(1.51-1.53)\end{array}$ & $\begin{array}{c}0.02 \\
(0.017-0.018)\end{array}$ \\
\hline 7 & - & - & + & + & + & - & - & $\begin{array}{c}0.03 \\
(0.032-0.033)\end{array}$ & $\begin{array}{c}1.51 \\
(1.51-1.52)\end{array}$ & $\begin{array}{c}0.017 \\
(0.017-0.018)\end{array}$ \\
\hline 8 & - & - & - & + & + & - & - & - & $\begin{array}{c}1.5 \\
(1.49-1.51)\end{array}$ & $\begin{array}{c}0.0178 \\
(0.0177-0.0179)\end{array}$ \\
\hline \multicolumn{11}{|c|}{$I+F C+P W P$} \\
\hline 9 & + & + & + & + & + & $\begin{array}{c}0.057 \\
(0.045-0.055)\end{array}$ & $\begin{array}{c}0.366 \\
(0.335-0.396)\end{array}$ & $\begin{array}{c}0.03 \\
(0.02-0.30)\end{array}$ & $\begin{array}{c}1.41 \\
(1.38-1.43)\end{array}$ & $\begin{array}{c}0.02 \\
(0.015-0.016)\end{array}$ \\
\hline 10 & - & + & + & + & + & - & $\begin{array}{c}0.278 \\
(0.270-0.286)\end{array}$ & $\begin{array}{c}0.005 \\
(0.005-0.010)\end{array}$ & $\begin{array}{c}2.07 \\
(2.03-2.11)\end{array}$ & $\begin{array}{c}0.01 \\
(0.006-0.007)\end{array}$ \\
\hline 11 & - & - & + & + & + & - & - & $\begin{array}{c}0.011 \\
(0.008-0.014)\end{array}$ & $\begin{array}{c}1.92 \\
(1.74-2.10)\end{array}$ & $\begin{array}{c}0.01 \\
(0.007-0.011)\end{array}$ \\
\hline 12 & - & - & - & + & + & - & - & - & $\begin{array}{c}1.51 \\
(1.49-1.54)\end{array}$ & $\begin{array}{c}0.018 \\
(0.016-0.019)\end{array}$ \\
\hline
\end{tabular}

$I$ - stands for infiltration data. *The range in the parenthesis is $\pm 95 \%$ confidence interval. - means that a parameter is not included in the parameter optimization process, + means that a parameter is included in the parameter optimization process. 
T a b l e 3. Calculated statistical criteria for the simulation assessment of different optimization scenarios $\left(\mathrm{R}^{2}=0.999\right)$

\begin{tabular}{|c|c|c|c|c|c|c|}
\hline Scenario & $\operatorname{SSE}\left(\mathrm{cm}^{3}\right)^{2}$ & $R M S E\left(\mathrm{~cm}^{3}\right)$ & $M B E\left(\mathrm{~cm}^{3}\right)$ & $A I C_{c}$ & $E F$ & $d$ \\
\hline 1 & 15874.56 & 30.56 & 7.48 & 130.88 & 1 & 1 \\
\hline 2 & 4512.83 & 16.29 & 4.51 & 105.74 & 1 & 1 \\
\hline 3 & 179.33 & 3.25 & -2.11 & 47.65 & 1 & 1 \\
\hline 4 & 542.21 & 5.65 & 2.27 & 63.61 & 1 & 1 \\
\hline 5 & 4021.96 & 15.38 & 4.2 & 107.54 & 1 & 1 \\
\hline 6 & 280.64 & 4.06 & 1.3 & 58.52 & 1 & 1 \\
\hline 7 & 141.79 & 2.89 & 0.33 & 43.66 & 1 & 1 \\
\hline 8 & 1817.84 & 10.34 & -5.17 & 84.18 & 1 & 1 \\
\hline 9 & 1329.57 & 8.84 & 2.18 & 88.73 & 1 & 1 \\
\hline 10 & 5953.03 & 18.71 & 5.84 & 110.45 & 1 & 1 \\
\hline 11 & 3390.64 & 14.12 & -3.81 & 97.62 & 1 & 1 \\
\hline 12 & 1069.10 & 7.93 & -3.41 & 75.15 & 1 & 1 \\
\hline
\end{tabular}
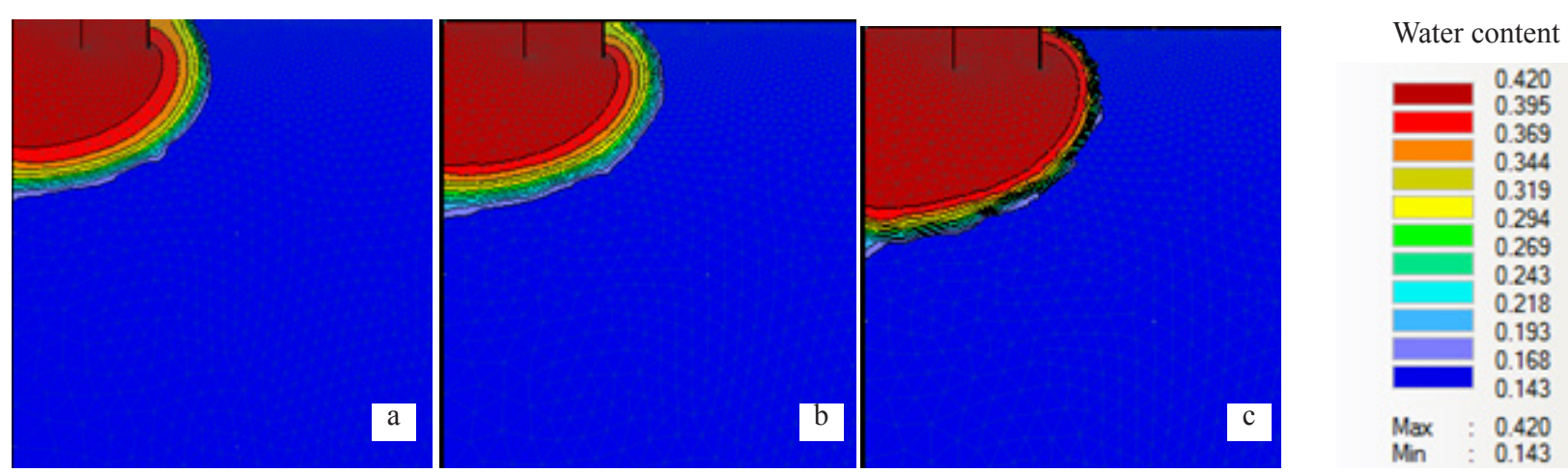

Fig. 3. Simulated 2D spatial distribution of water content in the soil profile after $300 \mathrm{~min}$ double-ring infiltration experiment for scenarios 1 (a), 5 (b), and 9 (c).

T a b l e 4. Ranking of twelve optimization scenarios using different statistical criteria (rank 1 means the best one, and rank 12 means the worst one)

\begin{tabular}{ccccc}
\hline Scenario & $S S E\left(\mathrm{~cm}^{3}\right)^{2}$ & $\begin{array}{c}R M S E \\
\left(\mathrm{~cm}^{3}\right)\end{array}$ & $M B E\left(\mathrm{~cm}^{3}\right)$ & $A I C_{c}$ \\
\hline 1 & 12 & 12 & 12 & 12 \\
2 & 10 & 10 & 9 & 9 \\
3 & 2 & 2 & 3 & 2 \\
4 & 4 & 4 & 5 & 4 \\
6 & 9 & 9 & 8 & 10 \\
7 & 3 & 3 & 2 & 3 \\
8 & 1 & 1 & 1 & 1 \\
9 & 7 & 7 & 10 & 6 \\
10 & 6 & 6 & 4 & 7 \\
11 & 11 & 11 & 11 & 11 \\
12 & 8 & 8 & 7 & 8 \\
\hline
\end{tabular}

\section{DISCUSSION}

According to Table 3, there was a high correlation between the measured and fitted cumulative infiltration data in all scenarios $\left(\mathrm{R}^{2}=0.999\right)$. However, the $\mathrm{R}^{2}$ values were essentially the same in all cases, and could not be a good criterion to compare the scenarios. The values of the $d$ index and $E F$ indicated the adequacy of the model in all scenarios, but again they could not be good criteria for comparison in this condition.

Based on the other statistical criteria, scenario 7 , in which parameters $\alpha, n$, and $K_{\mathrm{s}}$ were fitted using the infiltration data plus FC (as additional data) was the best one (Table 3). In other words, by reducing the number of fitting parameters in the soil hydraulic model from 5 to 3 , the optimization model is improved in agreement with the findings of Šimůnek et al. (2001). They reported that uncertainty is generally reduced when a limited number of parameters are used in the optimization studies. Hopmans et al. (2002) also reported that nonuniqueness would be diminished by decreasing the number of parameters to be optimized in the inverse solution methods. In fact, a flow 
T a b l e 5. Correlation matrix for soil hydraulic parameters $\alpha$ and $n$ in two optimization scenarios

\begin{tabular}{ccccccc}
\hline & Scenario 4 & & & \multicolumn{3}{c}{ Scenario 8 } \\
\cline { 1 - 2 } \cline { 5 - 6 } \cline { 5 - 6 }$\alpha$ & $\alpha$ & $n$ & & $\alpha$ & $n$ \\
\hline$n$ & 1.00 & & & $\alpha$ & 1.00 & \\
& -0.99 & 1.00 & & $n$ & -0.96 & 1.00 \\
\hline
\end{tabular}

experiment designed for inverse modelling should include measurements that are most sensitive to changes in the optimized parameters, thereby eliminating ill-posedness (Hopmans et al., 2002).

Sensitivity analysis can help to reduce the number of parameters in the optimization process by removing insensitive parameters. Moreover, sensitivity and parameter uncertainty are inversely related; that is, highly-sensitive measured variables would result in small parameter uncertainties for a given measurement error. In this study, cumulative infiltration was least sensitive to $l$ and $\theta_{\mathrm{r}}$ (Fig. 2), so by assuming $\theta_{\mathrm{r}}$ as a constant value (ie in scenarios 2, 6, and 10), the estimation of the parameters was improved (Table 1). This finding is in line with other studies stating that sensitivity to the pore-connectivity parameter $(l)$ is the lowest (Abbasi et al., 2003). Among the Mualemvan Genuchten hydraulic parameters, as mentioned by Ritter et al. (2004), $\theta_{\mathrm{s}}$ has a clear physical meaning and can be measured directly. Therefore, the number of soil hydraulic parameters for optimization was reduced to $3(\alpha, n$, and $K_{\mathrm{s}}$ ) in scenarios 3, 7, and 11. Scenarios 3 and 7 had the best results in the simulation according to different criteria (Table 4). By removing $\alpha$ (as a less sensitive parameter), the simulation was only improved in scenario 12 , but in scenarios 4 and 8 , the simulation error increased (Table 3 ). It seems that this is due to the high correlation between these two parameters, which is achieved through the correlation matrix (Table 5).

On the other hand, using FC as an additional predictor decreased the simulation error: SSE, RMSE, MBE, and $A I C_{c}$ decreased in these scenarios when compared with those with solely cumulative infiltration data as an input. Many researchers have reported that cumulative infiltration data do not provide enough information to obtain a unique set of optimized parameters, and some additional information is needed to yield a unique set of optimized parameters in inverse problems (Hopmans et al., 2002; Nakhaei and Šimůnek, 2014; Ritter et al., 2004; Russo et al., 1991). Such additional information could consist of pressure heads and/or water contents (Šimůnek and van Genuchten, 1996), solute concentrations (Abbasi et al., 2003), or temperatures (Nakhaei and Šimůnek, 2014) measured at a certain depth along the soil profile. However, our simulation results show that the simultaneous use of FC and PWP as an input increased the simulation error (Table 3 ).
A typical soil water retention curve usually consists of three zones: capillary saturation, desaturation, and residual saturation zones (Sillers et al., 2001). The FC is located in the low matric suction range of the desaturation zone, but PWP is located in the dry range (ie residual saturation zone). The FC is mainly affected by soil structure, poresize distribution, and continuity. It seems that a relatively low suction value associated with FC can be better linked with determination of soil hydraulic properties under ponded infiltration than to PWP. In other words, saturated flow in ponded infiltration is also governed by soil structure through the pore space characteristics. Therefore, using FC as a predictor could be expected to increase the efficacy of prediction of soil hydraulic parameters. Si and Kachanoski (2000) believed that the usefulness of additional data may depend on its sensitivity to the soil hydraulic parameters, the independence of the existing observations, and the measurement error.

\section{CONCLUSIONS}

1. HYDRUS-2D/3D software to simulate water infiltration through double-ring infiltrometers into a loamy soil profile we used. The results showed that the numerical inverse solution of double-ring infiltrometers data provided a relatively simple, yet reliable alternative method for determining the soil hydraulic properties.

2. By reducing the number of parameters involved in the optimization process, the simulation error is reduced. Therefore, sensitivity analysis would be required to identify the sensitive parameters. Using prior information for insensitive parameters (eg residual water content) or soil hydraulic parameters that can be easily measured independently (eg saturated water content) is effective in obtaining reliable answers.

3. Including additional data such as independently measured water content at the pressure head of $-330 \mathrm{~cm}$ (ie field capacity), as in our study, is suggested to better optimize/define the soil hydraulic functions. It is noticeable that although it is expected that additional data might lead to improved results, it seems that using both field capacity and permanent wilting point data as an input could not enhance the likelihood of uniqueness and stability of the inverse solution in the estimation process.

\section{REFERENCES}

Abbasi F., 2015. Advanced soil physics. Tehran University Publication, Iran.

Abbasi F., Šimůnek J., Feyen J., van Genuchten M.Th., and Shouse P.J., 2003. Simultaneous inverse estimation of soil hydraulic and solute transport parameters from transient field experiments: homogeneous soil. Trans. ASAE, 46(4), 1085-1095.

Akaike H., 1974. A new look at the statistical model identification. IEEE Trans Automat Contr., 19, 716-723. 
Alletto L., Pot V., Giuliano S., Costes M., Perdrieux F., and Justes E., 2015. Temporal variation in soil physical properties improves the water dynamics modeling in a conventionally-tilled soil. Geoderma, 243-244, 18-28.

Asgarzadeh H., Mosaddeghi M.R., Dexter A.R., Mahboubi A.A., and Neyshabouri M.R., 2014. Determination of soil available water for plants: consistency between laboratory and field measurements. Geoderma, 226-227, 8-20.

Bitterlich S., Durner W., Iden S.C., and Knabner P., 2004. Inverse estimation of the unsaturated soil hydraulic properties from column outflow experiments using free-form parameterizations. Vadose Zone J., 3, 971-981.

Bohne K., Roth C., Leij F.J., and van Genuchten M.Th., 1993. Rapid method for estimating the unsaturated hydraulic conductivity from infiltration measurements. Soil Sci., 55, 237-244.

Burnham K.P. and Anderson D.R., 2004. Multimodel inference: Understanding AIC and BIC in model selection. Sociol. Methods Res., 33, 261-304.

Damodhara Rao M., Raghuwanshi N.S., and Singh R., 2006. Development of a physically based 1D-infiltraton model for irrigated soils. Agric. Water Manag., 85, 165-174.

El-Nesr N.M., Alazba A.A., and Šimůnek J., 2014. HYDRUS simulations of the effects of dual-drip subsurface irrigation and a physical barrier on water movement and solute transport in soils. Irrig. Sci., 32, 111-125.

Hopmans J.W., Šimůnek J., and Bristow K.L., 2002. Indirect estimation of soil thermal properties and water flux from heat pulse measurements: Geometry and dispersion effects. Water Resour. Res., 38(1), 701-714.

Kandelous M.M., and Šimůnek J., 2010. Numerical simulations of water movement in a subsurface drip irrigation system under field and laboratory conditions using HYDRUS-2D. Agric. Water Manag., 97, 1070-1076.

Mualem Y., 1976. A new model for predicting the hydraulic conductivity of unsaturated porous media. Water Resour. Res., 12(3), 513-522.

Nakhaei M. and Šimůnek J., 2014. Parameter estimation of soil hydraulic and thermal property functions for unsaturated porous media using the HYDRUS-2D code. J. Hydrol. Hydromech., 62(1), 7-15.

Nash J.E. and Sutcliffe J.V., 1970. River flow forecasting through conceptual models. Part I: a discussion of principles. J. Hydrol., 10, 282-290.

Pollalis E.D. and Valiantzas J.D., 2015. Isolation of a 1D infiltration time interval under ring infiltrometers for determining sorptivity and saturated hydraulic conductivity: numerical, theoretical, and experimental approach. J. Irrig. Drain. Eng., 141(2), 10.1061/(ASCE)IR.1943-4774.0000796.

Ramos T.B., Šimůnek J., Gonçalves M.C., Martins J.C., Prazeres A., and Pereira L.S., 2012. Two-dimensional modeling of water and nitrogen fate from sweet sorghum irrigated with fresh and blended saline waters. Agric. Water Manag., 111, 87-104.

Rashid N.S.A., Askari M., Tanaka T., Šimůnek J., and van Genuchten M.Th., 2015. Inverse estimation of soil hydraulic properties under oil palm trees. Geoderma, 241-242, 306-312.
Reynolds W.D., Elrick D.E., and Youngs E.G., 2002a. Ring or cylinder infiltrometers (vadose zone). In: Dane, J.H., Topp, G.C. (Eds.): Methods of Soil Analysis. Part 4. Physical Methods. SSSA No. 5, Soil Science Society of America, Inc. Madison, WI, pp. 818-820.

Reynolds W.D., Elrick D.E., and Youngs E.G., 2002b. Singlering and double or concentric-ring infiltrometers. In: Dane, J., Topp, G.C. (Eds): Methods of Soil Analysis. Part 4 Physical Methods. SSSA No. 5, Soil Science Society of America, Inc. Madison, WI, pp, 821-826.

Ritter A., Munõz-Carpena R., Regalado C.M., Vanclooster M., and Lambot S., 2004. Analysis of alternative measurement strategies for the inverse optimization of the hydraulic properties of a volcanic soil. J. Hydrol., 295, 124-139.

Russo D., Bresler E., Shani U., and Parker J.C., 1991. Analysis of infiltration events in relation to determining soil hydraulic properties by inverse problem methodology. Water Resour. Res., 27, 1361-1373.

Schaap M.G., Leij F.J., and van Genuchten M.Th., 2001. ROSETTA: a computer program for estimating soil hydraulic parameters with hierarchical pedotransfer functions. J. Hydrol., 251,163-176.

Si B.C. and Kachanoski R.G., 2000. Estimating soil hydraulic properties during constant flux infiltration: Inverse procedures. Soil Sci. Soc. Am. J., 64, 439-449.

Sillers W.S., Fredlund D.G., and Zakerzadeh N., 2001. Mathematical attributes of some soil-water characteristic curve models. Geotech. Geol. Eng., 19, 243-283.

Šimůnek J. and van Genuchten M.Th., 1996. Estimating unsaturated soil hydraulic properties from tension disc infiltrometer data by numerical inversion. Water Resour. Res., 32(9), 2683-2696.

Šimůnek J., Wendroth O., and van Genuchten M.Th., 1998. Parameter estimation analysis of the evaporation method for determining soil hydraulic properties. Soil Sci. Soc. Am. J., 62, 894-905.

Šimůnek J., Wendroth O., Wypler N., and van Genuchten M.Th., 2001. Non-equilibrium water flow characterized by means of upward infiltration experiments. Eur. J. Soil Sci., 52(1), 13-24.

Šimůnek J., van Genuchten M.Th., and Šejna M., 2008. Development and applications of the HYDRUS and STANMOD software packages and related codes. Vadose Zone J., 7(2), 587-600.

Šimůnek J., van Genuchten M. Th., and Šejna M., 2011. The HYDRUS Software Package for Simulating Two- and Three-Dimensional Movement of Water, Heat, and Multiple Solutes in Variably-Saturated Media, Technical Manual, Version 2.0, PC Progress, Prague, Czech Republic.

van Genuchten M.Th., 1980. A closed-form equation for predicting the hydraulic conductivity of unsaturated soils. Soil Sci. Soc. Am. J., 44(5), 892-898.

Willmott C.J., 1981. On the validation of models. Physical Geography, 2, 184-194.

Wöhling T. and Vrugt J.A., 2011. Multiresponse multilayer vadose zone model calibration using Markov chain Monte Carlo simulation and field water retention data. Water Resour. Res., 47, W04510. doi: 10.1029/2010WR009265. 